\title{
Haulout site selection by southern elephant seals at Marion Island
}

\author{
T.W. Mulaudzi ${ }^{1,2^{*}}$, G.J.G. Hofmeyr ${ }^{2}$, M.N. Bester ${ }^{2}$, S.P. Kirkman², P.A. Pistorius², \\ F.C. Jonker', A.B. Makhado², J.H. Owen ${ }^{3} \&$ R.J. Grimbeek ${ }^{3}$ \\ ${ }^{1}$ Mammal Research Institute, Department of Zoology and Entomology, University of Pretoria, Pretoria, 0002 South Africa \\ ${ }^{2}$ National Zoological Gardens of South Africa, P.O Box 754, Pretoria, 0002 South Africa \\ ${ }^{3}$ Department of Statistics, University of Pretoria, Pretoria, 0002 South Africa \\ Submitted 18 March 2006. Accepted 19 September 2007
}

\begin{abstract}
Using data from an ongoing mark-resight programme at Marion Island, we tested empirically whether southern elephant seals prefer certain terrestrial sites to others during the breeding, moulting and winter haulouts, and whether the pattern of site use is the same for different age and sex groups. Southern elephant seals preferred some sites, while discriminating against other sites, with different age and sex classes using different sites for certain haulout events. Wintering young animals did not show strong site selection. Some popular sites were used for all haulouts by all age and sex groups, and apparently have all the requirements of a good site for terrestrial haulout by southern elephant seals. Site selection becomes more apparent with age, suggesting the role of haulout experience in site selection.
\end{abstract}

Key words: southern elephant seal, Mirounga leonina, Marion Island, age group, haulout, site selection.

\section{INTRODUCTION}

Southern elephant seals, Mirounga leonina, forage at sea and come to land for breeding, moulting, and resting (winter). Participation and timing of the different haulouts depend on the age, sex and social status of the animals (Hofmeyr 2000; Kirkman et al. 2001, 2003, 2004). The haulout pattern of southern elephant seals at Marion Island shows a high degree of organization, with the peak haulout of different age classes at different times (Condy 1979) and overlap between haulout events at the population scale (Kirkman et al. 2003). The elephant seal haulout sequence, characterized by a high degree of synchronization and annual regularity at Marion Island, is similar to that occurring at other elephant seals breeding grounds (Carrick et al. 1962; Condy 1979).

The breeding season of southern elephant seals at Marion Island begins with the hauling out of bulls in mid-August for the establishment of territories (Condy 1979). The pregnant cows follow early in September and they aggregate in groups called harems. The harems reach their maximum size around 15 October, when the number of adult females peaks with the maximum number of pups present about one week later (Condy 1979; Wilkinson 1992). After parturition and three weeks of lactation, individually, females mate with

*Author for correspondence. E-mail: tambu@zoo.ac.za the main bull and leave the harem for another feeding trip. The moult haulout is obligatory to all seals, except pups of the year, which commence moulting while still suckling. Timing of this haulout depends on age and sex, with yearlings of both sexes hauling out first from mid-November and remaining at moulting sites until late January. Subadults of both sexes and adult females haul out from mid-December to mid-March, and the adult males moult from late December to mid-April (Condy 1979). The third and least understood haulout is the one that mostly young elephant seals of both sexes participate in, with occasional appearances by adults. It is called the resting, or winter haulout (Hofmeyr 2000; Kirkman et al. 2001). For underyearlings and yearlings, participation in this event is similar for both sexes. Participation of older (subadult) animals depends more on sex than age because of the earlier reproductive maturity of females compared to males (Laws 1994; Bester \& Wilkinson 1994; Pistorius et al. 2001), with males more likely to haul out in winter (Kirkman et al. 2001).

The habitat of an animal varies with season and age and animals of different age groups might be found using different habitat during different seasons. Condy (1979) and Hofmeyr (2000) suggested that different age and sex classes of elephant seals prefer certain sites to others during the different 
haulouts at Marion Island. Elephant seals hauling out to moult and for the winter may also be seeking sites on the basis of characteristics that are not important for breeding seals (Hofmeyr 2000). The grey seal (Twiss et al. 2000) and the Galapagos sea lion (Wolf et al. 2005) have shown differential site usage between sexes and age groups in relation to site physiognomy.

The extensive mark-recapture programme of elephant seals on Marion Island that started in 1983 (Bester 1988) has resulted in the accumulation of a large database on recapture records. This database allows the investigation of spatial use of the terrestrial environment by southern elephant seals. This is important as terrestrial habitat requirements of seals allow conservation authorities to identify potential areas of conflict between humans and seal populations (Bradshaw et al. 2001), even on a local scale (Wilkinson \& Bester 1988; Thompson et al. 2001).

In this paper we quantitatively test the null hypotheses that (a) site preferences of southern elephant seals hauling out at Marion Island are the same for all terrestrial phases, and (b) site preferences do not vary between different age and sex classes.

\section{METHODS}

\section{Study area}

Marion Island $\left(46^{\circ} 54^{\prime} \mathrm{S}, 37^{\circ} 45^{\prime} \mathrm{E}\right)$ is $290 \mathrm{~km}^{2}$ in area, roughly oval in shape, measures $24 \mathrm{~km}$ from west to east and $14 \mathrm{~km}$ from north to south, and has a circumference of roughly $90 \mathrm{~km}$ (Wilkinson 1992). Most of the island coastline is irregular in configuration and composed of sea-pounded cliffs up to $15 \mathrm{~m}$ high. Initial irregularities in these areas have been smoothed over time to produce wide, open bays with stony beaches along the base of the cliffs (Wilkinson 1992). Beaches of an extremely rugged nature are characteristic of the exposed west coast, while the beaches on the leeward east coast are largely composed of pebbles, stones and rounded rocks (Wilkinson et al. 1987) with only two sandy beaches (Ship's Cove, MM065 in the east and Good Hope Bay, MM026 in the south). Elephant seals therefore have easy access to the terrestrial environment primarily on the east coast. The climate is basically oceanic, with modifications due to the topography of the island itself. A grid based on fractions of degrees (30 second intervals) of latitude and longitude was superimposed on the map of Marion Island (see Van Aarde 1979) to allow siting of the different beaches. The detailed description of beaches appears in Wilkinson et al. (1987) and includes the site code, beach name and grid block location. The main study area, on the east coast, was divided into 40 clearly-demarcated sites following Wilkinson et al. (1987). Each of these sites received a code, MM for Marion Island, followed by a three-digit number ranging from 001 to 068 (Fig. 1).

\section{Database}

The seal marking and resighting techniques used in this study are reported in full in Pistorius et al. (1999). Essentially weaned elephant seal pups (underyearlings) were double tagged each year since 1983 with colour coded Jumbo Rototags (Dalton Supplies Ltd, Henly-on-Thames, U.K.) at their sites of birth. Different colour combinations were used for each year in order to differentiate the cohorts. Each individual seal received one of a pair of exclusively three-digit numbered tags in the interdigital webbing of each hind flipper. Over the 18 years 1983-2001 more than 9000 animals were marked and some 55000 records of resights have been collected, forming the basis for the study.

\section{Data collection}

Tag resights during censuses were carried out every 10 days during the winter and the moult haulout between Storm Petrel Beach (MM051) and Kildalkey Beach (MM020) (Fig. 1). During the breeding season haulout, censuses and tag resights were performed on a seven-day cycle on this section of coast. The south coast sites at Watertunnel Stream and Good Hope Bay East and West were censused once every 10-20 days during the winter and moult haulout and on a 7-14-day cycle during the breeding haulout. From 1983 to 1989, censuses and hence tag resights, took place only from August of one year to May of the next year, which means that the winter haulout went largely unrecorded during these years. Complete winter records are available from 1990 onwards. It was assumed that the intensity and efficiency of search efforts during the study period was consistent (Pistorius et al. 1999) and that once an animal hauled out for a particular season, it was assumed to have selected that site and have not been to other sites for that particular haulout (Hofmeyr 2000), a reasonable assumption (Munyai 2006).

Male elephant seals attain sexual maturity at the age of five and attain social maturity at the age of 


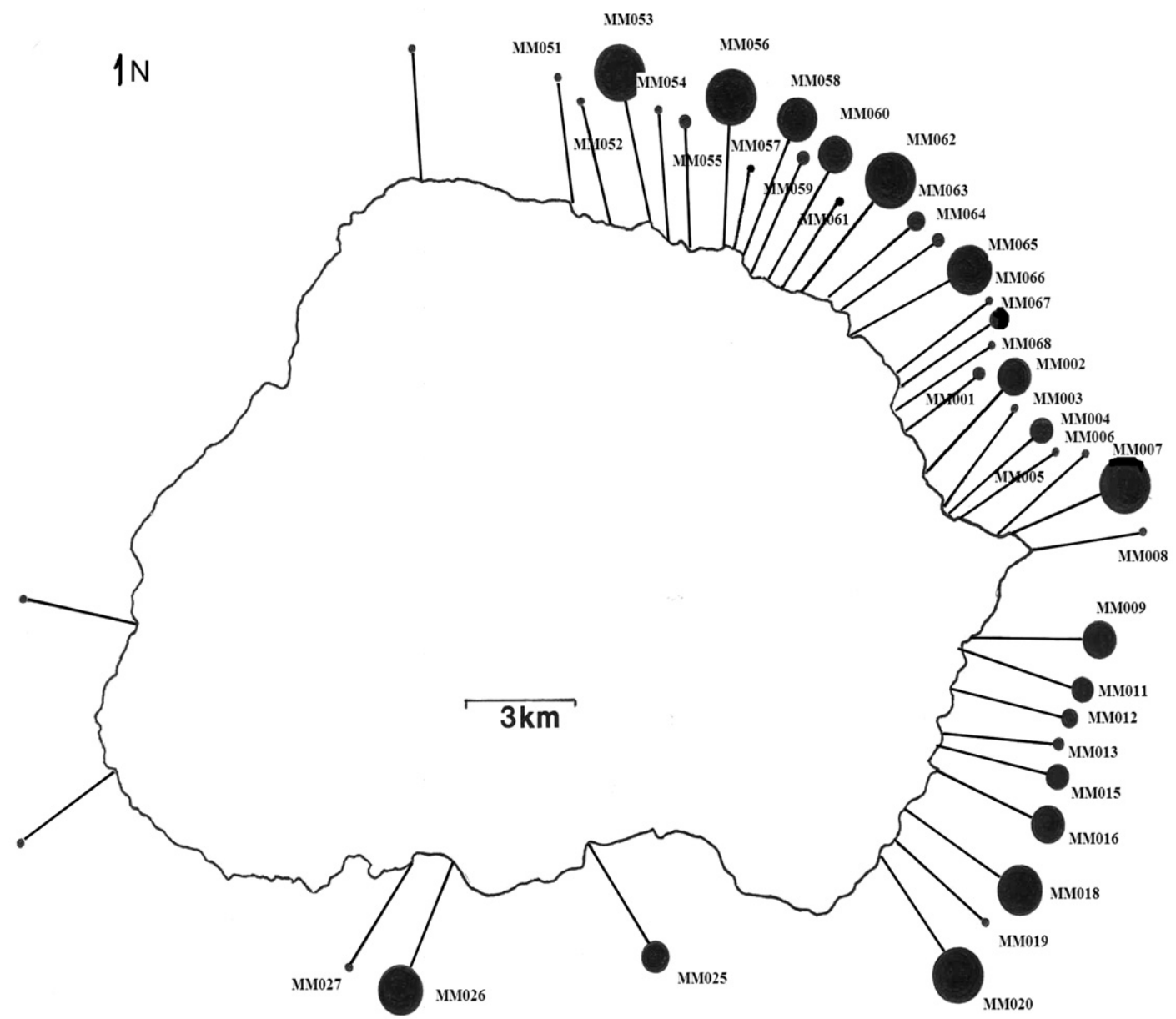

Fig. 1. The coastline of Marion Island showing the study area and sites (MM051 in the North to MM027 in the South). The size of each dot corresponds with the mean number of pups born at each site over the study period and hence the popularity of the different sites.

eight (Laws \& Le Boeuf 1994), but in the small Marion Island population they are able to hold harems as early as the age of six (Pistorius et al. 2001). The youngest females to give birth at Marion Island were three years old (Bester \& Wilkinson 1994), but any female between ages two and six that had not at any time been observed with a pup was considered subadult, with those that had been observed with pups considered adults, together with those that were seven years old and older that were fully recruited to the breeding population (Bester \& Wilkinson 1994; Pistorius et al. 2001).

Age and sex classifications of elephant seals at Marion Island followed Condy (1979) and are given below with class codes in brackets:

Pups = young of both sexes before the first pelagic sojourn (00); Underyearlings $=$ animals of both sexes under the age of one year (10); Yearlings = one-year-old animals of both sexes (20); Subadults = males two years and older but younger than six years (30); Females two years and older but below five years that have not been recorded with a pup during any breeding season (30); Adults $=$ males over six years of age (40), females $\geq 5$ years including all those that have been recorded with a pup during any breeding season (40). Bulls of age six that have been recorded present during the breeding season were considered adults (40) but the rest of six-year-old males were still considered subadults (30) following Kirkman et al. (2003).

For each beach visited on each occasion, and for each tagged animal found, the date, site code, tag 
colour combination (age), tag number, social status (the reason for the hauling out), and moulting stage (moulting progress) were recorded. The full suite of information collected during each census appears in Mulaudzi (2005).

\section{Data manipulation}

The moulting season extends from one calendar year to another. To enable the pooling of all the moulting season data together, and to assign moulting animals to a particular year, the moulting season data from January-May of each year were backdated by one year, e.g. animals moulting from January-May 1987 became the moulters of 1986. Southern elephant seals at Marion Island are assumed to age a year on 15 October, the peak of the breeding season haulout (Wilkinson 1992). For the ease of handling the data, a year was added to the age of all tagged seals at their first resighting during the breeding season, even if they were resighted before the peak of the breeding season haulout (15 October). This was done so that a breeding animal would have only one age during a particular breeding season.

All the data files from the various years were pooled. For each age class and particular haulout, frequencies of individual records for each of the 40 sites in the study area were calculated using the SAS 8.2 statistical package. To test for statistical significance in site preference, and for difference between male and female site choice, the standardized log-linear coefficient $(z)$, was computed for each site from the frequency of records for that site. The log-linear coefficient $(z)$ is considered as significant when $|z|=2.58$. Where the log-linear coefficient $(z)$ was $\geq 2.58$, the site was preferred, and where $z \leq-2.58$, the site was discriminated against. Where the $z$ score was $z \geq 2.58$ for males and $z \leq-2.58$ for females and vice versa, then there is a difference between males and females in the use of the site, with a positive value indicating increased usage of the site over the others (Agresti 1990).

\section{RESULTS}

During the study period almost all elephant seal terrestrial activities were restricted to the east coast of the island (with the exception of Watertunnel Beach (MM025) and Good Hope Bay (MM206) on the southern coast) where there are numerous popular sites for hauling out (Fig. 1).

(a) Underyearlings: during the winter haulout, underyearling elephant seals showed preference for 17 sites scattered all over the main study area and discriminated against seven sites (Table 1). There was no significant difference in site preference between male and female underyearlings during the winter haulout $(P=0.9100)$.

(b) Yearlings: during the moult haulout, yearling elephant seals showed some selection of sites, with 18 sites being preferred and 12 being disfavoured $(P<0.0001)$ (Table 2$)$. There was no significant difference in site preference between male and female yearlings during the moult haulout $(P=$ $0.9700)$, but with significantly more females hauling out for the moult $(\mathrm{M}, z=-3.308 ; \mathrm{F}, z=$ 3.308). The yearlings preferred 19 sites during the winter haulout, while eight sites were disfavoured $(P<0.0001)$ (Table 2). Males and females preferred the same sites during the winter haulout $(P=$ $0.4900)$, with significantly more females than males present during the winter $(\mathrm{M}, z=-3.051 ; \mathrm{F}$, $z=3.051$ at $P=0.0200$ ).

(c) Subadults: During the moult haulout, subadult elephant seals preferred 23 sites and 10 others were selected against $(P<0.0001)$ (Tables $2 \& 3$ ). There was a significant sex difference in site preference during the moult haulout, with subadult males showing interest in two sites (MM020 and MM065), for which subadult females showed no interest $(P=0.0080)$ (Tables $2 \& 3)$. There was no significant difference between the numbers of subadult males and females in this sample $(\mathrm{M}, z=$ 1.272; F, $z=-1.272)$ at $P=0.0003$. Eighteen sites were favoured and 10 sites selected against during the winter haulout by subadult elephant seals $(P<$ 0.0001 ) (Tables $2 \& 3$ ), but no difference in site preference between male and female subadults $(P=$ $0.4400)$. There was significantly more males than females in the winter sample $(\mathrm{M}, z=11.872 ; \mathrm{F}, z=$ -11.872) $(P<0.0001)$

(d) Adults: during the breeding season haulout, adult elephant seals showed preference for certain sites over others, with 16 sites being favoured and 12 being selected against $(P<0.0001)$ (Tables $2 \&$ $3)$. There was a significant difference in site preference between the sexes during the breeding season haulout, with adult females showing preference for seven sites that adult males showed no preference for $(P<0.0001)$. There was a significant difference between the numbers of males and females used in this sample (M, $z=-10.622 ; \mathrm{F}, z=$ $10.622, P<0.0001)$. Fourteen sites were favoured versus five sites being avoided during the moult haulout by adults $(P<0.0001)$ (Tables $2 \& 3)$. There was a significant difference in site preference 
Table 1. Results of the log-linear model applied to the contingency table for beach and sex for underyearlings during the winter haulout. The numbers in brackets are the $z$-scores, the standardized estimated log-linear coefficients, and are significant if $|z| \geq 2.58$.

\begin{tabular}{|c|c|c|c|c|c|c|}
\hline \multirow[t]{3}{*}{ Site } & \multicolumn{4}{|c|}{ Sex } & \multirow{2}{*}{\multicolumn{2}{|c|}{$\begin{array}{c}\text { Total } \\
(n=1919)\end{array}$}} \\
\hline & \multicolumn{2}{|c|}{ Females $(n=1000)$} & \multicolumn{2}{|c|}{ Males $(n=919)$} & & \\
\hline & Freq $(z)$ & $(\%)$ & Freq $(z)$ & $(\%)$ & Freq $(z)$ & $\%$ \\
\hline MM001 & $31(-1.089)$ & 3.06 & $34(1.089)$ & 3.67 & $65(5.178)$ & 3.35 \\
\hline MM002 & $48(-1.451)$ & 4.78 & $54(1.451)$ & 5.87 & $102(10.604)$ & 5.30 \\
\hline MM003 & $10(0.061)$ & 0.97 & $8(-0.061)$ & 0.84 & $18(-2.621)$ & 0.90 \\
\hline MM004 & $43(0.206)$ & 4.30 & $34(-0.206)$ & 3.71 & 77 (6.929) & 4.02 \\
\hline MM006 & $13(0.644)$ & 1.31 & $8(-0.644)$ & 0.87 & $21(-2.178)$ & 1.10 \\
\hline MM007 & $37(-0.036)$ & 3.71 & $31(0.036)$ & 3.33 & $68(5.607)$ & 3.53 \\
\hline MM008 & $2(0.324)$ & 0.15 & $1(-0.324)$ & 0.05 & $3(-4.324)$ & 0.10 \\
\hline MM009 & $23(0.896)$ & 2.31 & $14(-0.896)$ & 1.49 & $37(0.432)$ & 1.92 \\
\hline MM010 & $18(0.572)$ & 1.85 & $12(-0.572)$ & 1.36 & $30(-0.667)$ & 1.62 \\
\hline MM011 & $63(0.035)$ & 6.30 & $52(-0.035)$ & 5.69 & $115(12.31)$ & 6.01 \\
\hline MM012 & $21(1.215)$ & 2.09 & $11(-1.215)$ & 1.23 & $32(-0.484)$ & 1.68 \\
\hline MM013 & $22(-1.199)$ & 2.21 & $26(1.199)$ & 2.81 & $48(2.431)$ & 2.50 \\
\hline MM014 & 17 (1.219) & 1.80 & $9(-1.219)$ & 0.96 & $26(-1.306)$ & 1.40 \\
\hline MM015 & $41(-1.026)$ & 4.08 & $43(1.026)$ & 4.64 & 84 (8.063) & 4.35 \\
\hline MM016 & $20(-0.585)$ & 2.02 & $20(0.585)$ & 2.14 & 40 (1.129) & 2.08 \\
\hline MM017 & $5(0.810)$ & 0.50 & $2(-0.810)$ & 0.18 & $7(-4.102)$ & 0.35 \\
\hline MM018 & $66(-1.640)$ & 6.64 & $74(1.640)$ & 8.01 & $140(15.58)$ & 7.29 \\
\hline MM019 & $11(0.018)$ & 1.07 & $9(-0.018)$ & 1.00 & $20(-2.288)$ & 1.03 \\
\hline MM020 & $43(-1.445)$ & 4.32 & 49 (1.445) & 5.32 & $92(9.191)$ & 4.80 \\
\hline MM025 & $35(-0.273)$ & 3.60 & $32(0.273)$ & 3.54 & $67(5.635)$ & 3.57 \\
\hline MM026 & $12(0.214)$ & 1.17 & $9(-0.214)$ & 0.93 & $21(-2.134)$ & 1.05 \\
\hline MM027 & $1(-0.574)$ & 0.05 & $0(0.574)$ & 0.00 & $1(-3.749)$ & 0.03 \\
\hline MM051 & $10(-0.862)$ & 1.01 & $12(0.862)$ & 1.25 & $22(-1.951)$ & 1.13 \\
\hline MM052 & $4(-0.280)$ & 0.38 & $4(0.280)$ & 0.47 & $8(-4.095)$ & 0.43 \\
\hline MM053 & $45(-0.841)$ & 4.52 & $45(0.841)$ & 4.87 & $90(8.94)$ & 4.68 \\
\hline MM054 & $6(1.059)$ & 0.61 & $2(-1.059)$ & 0.20 & $8(-3.975)$ & 0.41 \\
\hline MM055 & $14(-1.219)$ & 1.41 & $18(1.219)$ & 1.95 & $32(-0.271)$ & 1.67 \\
\hline MM056 & 54 (1.098) & 5.36 & $35(-1.098)$ & 3.85 & $89(8.417)$ & 4.64 \\
\hline MM057 & $10(-1.789)$ & 0.99 & 17 (1.789) & 1.82 & $27(-1.22)$ & 1.39 \\
\hline MM058 & $30(-1.447)$ & 3.04 & 36 (1.447) & 3.90 & 66 (5.295) & 3.45 \\
\hline MM059 & $13(-0.677)$ & 1.28 & $14(0.677)$ & 1.55 & $27(-1.089)$ & 1.41 \\
\hline MM060 & $13(-1.050)$ & 1.31 & $16(1.050)$ & 1.76 & $9(-0.768)$ & 1.52 \\
\hline MM061 & $5(0.028)$ & 0.50 & $4(-0.028)$ & 0.47 & $63(-3.97)$ & 0.49 \\
\hline MM062 & $31(-0.724)$ & 3.20 & $32(0.724)$ & 3.53 & $49(5.034)$ & 3.36 \\
\hline MM063 & $26(-0.221)$ & 2.64 & $23(0.221)$ & 2.49 & $49(2.610)$ & 2.57 \\
\hline MM064 & $34(-0.744)$ & 3.42 & $34(0.744)$ & 3.73 & 68 (5.657) & 3.57 \\
\hline MM065 & $48(0.445)$ & 4.82 & $36(-0.445)$ & 3.95 & 84 (7.907) & 4.40 \\
\hline MM066 & $13(0.898)$ & 1.26 & $7(-0.898)$ & 0.80 & $20(-2.374)$ & 1.04 \\
\hline MM067 & $48(-0.343)$ & 4.81 & $43(0.343)$ & 4.73 & $91(9.058)$ & 4.77 \\
\hline MM068 & $12(-0.214)$ & 1.18 & $9(0.214)$ & 1.03 & $21(-2.134)$ & 1.11 \\
\hline Total & $1000(-2.418)$ & 100.03 & $919(2.418)$ & 99.99 & 1919 & 100.02 \\
\hline
\end{tabular}

Significance of factors: sex, $P=0.6400$; beach, $P<0.0001$; sex and beach, $P=0.9065$. 
Table 2. The numbers of sites favoured and discriminated against by southern elephant seals of different age groups during the different haulout events.

\begin{tabular}{|c|c|c|c|c|c|c|}
\hline & \multicolumn{2}{|c|}{ Breeding } & \multicolumn{2}{|c|}{ Moulting } & \multicolumn{2}{|c|}{ Wintering } \\
\hline & Favoured & Discriminated & Favoured & Discriminated & Favoured & Discriminated \\
\hline Underyearlings & n/a & n/a & $n / a$ & n/a & 17 & 7 \\
\hline Yearlings & $n / a$ & $\mathrm{n} / \mathrm{a}$ & $18(P<0.9700)$ & $12(P<0.9700)$ & $19(P<0.0001)$ & $8(P<0.0001)$ \\
\hline Subadults & $\mathrm{n} / \mathrm{a}$ & n/a & $23(P<0.0001)$ & $10(P<0.0001)$ & $18(P<0.0001)$ & $10(P<0.0001)$ \\
\hline Adults & $16(P<0.0001)$ & $12(P<0.0001)$ & $14(P<0.0001)$ & $5(P<0.0001)$ & $\mathrm{n} / \mathrm{a}$ & $\mathrm{n} / \mathrm{a}$ \\
\hline
\end{tabular}

between the sexes during the moult haulout, with adult males showing interest for two sites (MM002 and MM025) that adult females showed no preference for $(P<0.0001)$ (Tables $2 \& 3)$. There was a significant difference between the numbers of males and females used in this sample $(\mathrm{M}, \mathrm{z}=$ $-16.431 ; F, z=16.431)(P<0.0001)$.

\section{DISCUSSION}

Habitat selection is influenced by two types of factors, namely, physiological tolerance limits and choice factors (Miller \& Harley 1996). While some animals are influenced in their choice for a place to live by the physical environment, some are influenced by the densities of conspecifics.

Whatever the reasons, this study unequivocally showed that elephant seals prefer certain site to others for their terrestrial activities as there is almost no overlap between preferred sites and non-preferred sites for the different haulouts of elephant seals at Marion Island. Only one site (MM006) appeared amongst both the favoured sites and the non-preferred sites (Table 3 ) for different haulouts. About $50 \%$ of all the preferred sites were selected by all age groups and for all the haulouts, and about $50 \%$ of all non-preferred sites were discriminated against by all age groups and for all the haulouts.

Hofmeyr (2000), suggested that young elephant seals (underyearlings and yearlings) hauling out for the winter and the moult do not seek sites on the same basis as adult animals hauling out to breed. All that young seals appear to need is a beach that is accessible and flat (Hofmeyr 2000), but older animals (subadults and adults) are expected to be more selective because of previous haulout experience. This was supported by our findings. Young animals appeared to be more generalists, using almost all the preferred sites for all the haulouts. Preference becomes more apparent with age. For adults, there were sites that were used significantly more for breeding and significantly less for moulting, while others were used exclusively for moulting. This suggests that to a degree, elephant seals use different sites for the different haulouts although some sites are used for all the haulout events.

Difference in site use between males and females was apparent in subadult and adult elephant seals only during the moulting season. The four sites (MM020 \& MM065 and MM002 \& MM025) that were preferred more by subadult and adult males than females of the same age classes have moult wallows at the back of the beach closer to shore compared to other beaches, but with beach type(s) difficult to negotiate from the shore. Carrick et al. (1962) also reported that adult male seals prefer moulting closer to shore because of their tendency of going into short feeding phases during the moult. However, a tendency to go on short feeding phases by adult males during the moult could not be confirmed in the present study. By contrast, during the breeding season, seven sites were preferred significantly more by females than by males. This difference can be explained by the elephant seals' polygynous breeding system (Laws 1956; Carrick et al. 1962) because the beaches where the difference in site selection was apparent were all main breeding beaches (present study).

It can be concluded that there is a differential site usage by southern elephant seals of different age and sex classes during the three different haulouts. The differential site use seems to depend on haulout experience, and thus age and hence familiarity with the island haulout sites. Pistorius et al. (2002) also suggested that animals participating in the winter haulout have higher natal site fidelity during all the subsequent haulouts, as opposed to those that do not.

Choosing a place to live does not necessarily imply a conscious choice, or that individuals make a critical evaluation of the entire constellation of factors confronting them. Often the choice is an innate reaction to certain aspects of the environ- 
Table 3. The listing of unfavoured and favoured sites for the haulouts of different age classes of elephant seals during their respective haulout events.

\begin{tabular}{|c|c|c|c|c|c|c|}
\hline 10 winter & 20 moult & 20 winter & 30 moult & 30 winter & 40 breed & 40 moult \\
\hline \multicolumn{7}{|c|}{ Unfavoured sites } \\
\hline \multirow[t]{2}{*}{ MM003 } & & & & & MM003 & \\
\hline & & & & MM006 & MM006 & \\
\hline \multirow[t]{4}{*}{ MM008 } & MM008 & MM008 & MM008 & MM008 & MM008 & \\
\hline & & & MM010 & & MM010 & \\
\hline & MM012 & & MM012 & MM012 & & \\
\hline & MM014 & MM014 & MM014 & MM014 & MM014 & MM014 \\
\hline \multirow[t]{2}{*}{ MM017 } & MM017 & MM017 & MM017 & MM017 & & MM017 \\
\hline & MM019 & MM019 & MM019 & MM019 & & \\
\hline \multirow[t]{2}{*}{ MM027 } & MM027 & MM027 & MM027 & MM027 & MM027 & MM027 \\
\hline & MM051 & & & MM051 & MM051 & \\
\hline MM052 & MM052 & & & & MM052 & \\
\hline MM054 & MM054 & MM054 & MM054 & & MM054 & MM054 \\
\hline \multirow[t]{3}{*}{ MM061 } & MM061 & MM061 & MM061 & MM061 & MM061 & MM061 \\
\hline & MM066 & & & & MM066 & \\
\hline & MM068 & MM068 & MM068 & MM068 & MM068 & \\
\hline \multicolumn{7}{|c|}{ Favoured sites } \\
\hline MM001 & MM001 & MM001 & MM001 & MM001 & & MM001 \\
\hline MM002 & MM002 & MM002 & MM002 & MM002 & MM002 & MM002 \\
\hline \multirow[t]{2}{*}{ MM004 } & MM004 & MM004 & MM004 & MM004 & MM004 & \\
\hline & & & MM006 & & & \\
\hline \multirow[t]{2}{*}{ MM007 } & MM007 & MM007 & MM007 & MM007 & MM007 & MM007 \\
\hline & & & MM009 & & & \\
\hline \multirow{2}{*}{ MM011 } & MM011 & MM011 & MM011 & MM011 & MM011 & \\
\hline & MM013 & MM013 & MM013 & & & \\
\hline \multirow[t]{2}{*}{ MM015 } & MM015 & MM015 & MM015 & MM015 & MM015 & MM015 \\
\hline & & MM016 & MM016 & MM016 & MM016 & \\
\hline MM018 & MM018 & MM018 & MM018 & MM018 & MM018 & MM018 \\
\hline MM020 & MM020 & MM020 & MM020 & MM020 & MM020 & MM020 \\
\hline \multirow[t]{2}{*}{ MM025 } & MM025 & MM025 & MM025 & MM025 & MM025 & MM025 \\
\hline & MM026 & & MM026 & & MM026 & MM026 \\
\hline \multirow[t]{2}{*}{ MM053 } & MM053 & MM053 & MM053 & MM053 & MM053 & MM053 \\
\hline & & & MM055 & & & MM055 \\
\hline \multirow[t]{2}{*}{ MM056 } & MM056 & MM056 & MM056 & MM056 & MM056 & MM056 \\
\hline & & & MM057 & & & MM057 \\
\hline \multirow[t]{2}{*}{ MM058 } & & MM058 & MM060 & MM058 & MM058 & \\
\hline & & & & & MM060 & \\
\hline MM062 & MM062 & MM062 & MM062 & MM062 & MM062 & MM062 \\
\hline MM063 & MM063 & MM063 & MM063 & MM063 & & \\
\hline MM064 & MM064 & MM064 & MM064 & MM064 & & \\
\hline MM065 & MM065 & MM065 & MM065 & MM065 & MM065 & MM065 \\
\hline MM067 & MM067 & MM067 & & MM067 & & \\
\hline
\end{tabular}

Key: $\mathbf{1 0}$ = underyearlings; and $\mathbf{2 0}$ = yearlings; $\mathbf{3 0}$ = subadults; $\mathbf{4 0}$ = adults.

ment (Feldhamer et al. 1999). Social influences (Galimberti et al. 2000a,b), population density (Pistorius et al. 2002) and the particular physiognomic features of the sites (e.g. van Aarde 1979; Twiss et al. 2000; Wolf et al. 2005; Setsaas et al., 2008) that were favoured or discriminated against in the present study may all have played a role in haulout site selection by southern elephant seals (Setsaas et al. 2008. These will be considered together in another study.

\section{ACKNOWLEDGEMENTS}

We thank the Department of Environmental Affairs and Tourism (DEAT) for providing logistical 
support for this work, on the advice of the South African Committee for Antarctic Research (SACAR). This material is also based upon work supported by the National Research Foundation (NRF). Any opinion, findings and conclusions or recommendations expressed in this material are those of the authors and therefore the NRF does not accept any liability in regard thereto. The Lutheran Scholarship Fund (LSF) provided a student bursary while DEAT provided salaries and logistic support during the study period. Craig Saunders, Steve Atkinson, Anton Hunt, Peter Bartlett, Ian Wilkinson, Charlie Pascoe, Jaco Swart, Rory Heather-Clark, Sampie Ferreira, Andrè la Cock, Hendrik Pansegrouw, Francois Roux, Johan Fourie, Johannes de Lange, Johannes Klopper, Derrick Shingwenyana, Mike de Maine, Tendamudzimu Mathagu, and Bianca Harck were responsible when we were not in the field. The Marion 58 expedition, especially Samantha Petersen and Wilna Wilkinson, are thanked for support and help with fieldwork.

\section{REFERENCES}

AGRESTI, A. 1990. Categorical Data Analysis. John Wiley \& Sons, New York.

BESTER, M.N. 1988. Marking and monitoring studies of the Kerguelen stock of southern elephant seals Mirounga leonina and their bearing on biological research in the Vestfold Hills. Hydrobiologia 165: 269-277.

BESTER, M.N. \& WILKINSON, I.S. 1994. Population ecology of southern elephant seals at Marion Island. In: Elephant Seals: Population Ecology, Behavior and Physiology, (eds) B.J. Le Boeuf \& R.M. Laws, pp. 85-97. University of California Press, Berkeley.

BRADSHAW, C.J.A., DAVIS, L.S., PURVIS, M., ZHOU, Q. \& BENWELL, G.L. 2001. Using artificial neural networks to model the suitability of coastline for breeding by New Zealand fur seals (Arctocephalus forsteri). Ecological Modelling 148: 111-131.

CARRICK, R., CSORDAS, S.E. \& INGHAM, S.E. 1962. Studies on the southern elephant seal Mirounga leonina (L.). IV. Breeding and development. Commonwealth Science and Industrial Research Organizations, Wildlife Research 7: 42-48.

CONDY, P.R. 1979. Annual cycle of the southern elephant seal Mirounga leonina (Linn.) at Marion Island. South African Journal of Zoology 14: 95-102.

FELDHAMER, G.A., DRICKAMER, L.C., VESSY S.H. \& MERRIT, J.F. 1999. Mammalogy: Adaptation, Diversity, and Ecology. WCB McGraw-Hill. New York.

GALIMBERTI, F., BOITANI, L. \& MARZETTI, I. 2000a. The frequency and cost of harassment in southern elephant seals. Ethology, Ecology and Evolution 12: 345-365.

GALIMBERTI, F., BOITANI, L. \& MARZETTI, I. 2000b.
Harassment during arrival on land and departure to sea in southern elephant seals. Ethology, Ecology and Evolution 12: 389-404.

HOFMEYR, G.J.G. 2000. Dispersal and dispersion of southern elephant seals at Marion Island. M.Sc. thesis, University of Pretoria, Pretoria.

KIRKMAN, S.P., BESTER, M.N., PISTORIUS, P.A., HOFMEYR G.J.G., OWEN, R. \& MECENERO, S. 2001. Participation in the winter haulout by southern elephant seals, Mirounga leonina. Antarctic Science 13(4): 380-384.

LAWS, R.M. 1956. The elephant seal (Mirounga leonina Linn.). II. General, social and reproductive behaviour. Falkland Islands Dependencies Survey Scientific Report 13: $1-88$.

LAWS, R.M. 1994. History and present status of southern elephant seal populations. In: Elephant Seals: Population Ecology, Behavior and Physiology, (eds) B.J. Le Boeuf \& R.M. Laws, pp. 49-65. University of California Press. Berkeley.

MILLER, S.A. \& HARLEY, J.P. 1996. Zoology. Wm.C. Brown. Sydney.

MULAUDZI, T.W. 2005. Terrestrial haulout site usage by southern elephant seals, Mirounga leonina, at Marion Island. M.Sc. thesis, University of Pretoria, Pretoria.

MUNYAI, F.M. 2006. Intersite movement by southern elephant seals ashore at Marion Island. M.Sc. thesis, University of Pretoria, Pretoria.

PISTORIUS, P.A., BESTER, M.N. \& KIRKMAN, S.P. 1999. Survivorship of the declining population of southern elephant seals, Mirounga leonina, in relation to age, sex and cohort. Oecologia 121: 201-211.

PISTORIUS, P.A., BESTER, M.N., KIRKMAN, S.P., \& TAYLOR, F.E. 2001. Temporal changes in the fecundity and age at sexual maturity of southern elephant seals at Marion Island. Polar Biology 24: 343-348.

PISTORIUS, P.A., KIRKMAN, S.P., BESTER, M.N. \& TAYLOR, F.E. 2002. Implications of the winter haulout for future survival and resighting probability of southern elephant seals at Marion Island. South African Journal of Wildlife Research 32(1): 59-63.

SETSAAS, T.H., BESTER, M.N., VAN NIEKERK, J.H., ROUX, J.P. \& HOFMEYR, G.J.G. 2008. Dispersion during the moult haulout of southern elephant seals at the Courbet Peninsula, Iles Kerguelen. Polar Biology 31: 249-253.

THOMPSON, P.M., VAN PARJIS, S. \& KOVACS, K.M. 2001. Local declines in the abundance of harbour seals: implications for the designation and monitoring of protected areas. Journal of Applied Ecology 38: 117-125.

TWISS, S.D., CAUDRON A., POMEROY, P.P., THOMAS, C.J. \& MILLS, J.P. 2000. Fine scale topographical correlates of behavioural investment in offspring by female grey seal, Halichoerus grypus. Animal Behaviour 59: 327-338.

VAN AARDE, R.J. 1979. Distribution and density of the feral house cat, Felis catus, on Marion Island. South African Journal of Antarctic Research 9:14-19.

VAN AARDE, R.J. 1980. Harem structure of the southern elephant seal (Mirounga leonina) at Kerguelen Island. 
Review de Ecologie (Terre et la Vie). 34: 31-44.

WILKINSON, I.S., PASCOE, C. \& BESTER, M.N. 1987. Marion Island beach descriptions. Typescript, Mammal Research Institute, University of Pretoria, Pretoria.

WILKINSON, I.S. \& BESTER, M.N. 1988. Is onshore human activity a factor in the decline of the southern elephant seal? South African Journal of Antarctic Research 18(1): 14-17.
WILKINSON, I.S. 1992. Factors affecting reproductive success of southern elephant seals, Mirounga leonina, at Marion island. Ph.D. thesis, University of Pretoria, Pretoria.

WOLF, J.B.W., KAUERMANN, G. \& TRILLMICH, F. 2005. Males in the shade: habitat use and sexual segregation in the Galápagos sea lion (Zalophus californianus wollebaeki). Behavioural Ecology and Sociobiology 59: 293-302.

Responsible Editor: C.L. Griffiths 


\section{Errata}

In the article 'Haulout site selection by southern elephant seals at Marion Island' that appeared in African Zoology 43(1):25-33 (April 2008), the institutional affiliations of the authors should have read:

T.W. Mulaudzi" ${ }^{*}$, G.J.G. Hofmeyr', M.N. Bester', S.P. Kirkman', P.A. Pistorius', F.C. Jonker', A.B. Makhado', J.H. Owen² \& R.J. Grimbeek²

${ }^{1}$ Mammal Research Institute, Department of Zoology and Entomology, University of Pretoria, Pretoria, 0002 South Africa ${ }^{2}$ Department of Statistics, University of Pretoria, Pretoria, 0002 South Africa

*Author for correspondence. Present address: National Zoological Gardens of South Africa, P.O. Box 754, Pretoria, 0002 South Africa. E-mail: tambu@zoo.ac.za 